\title{
Aromaterapötik Gül Uçucu Yağının Bakteriyel Quorum Sensing ve Biyofilm Üretimine Karşı İnhibisyon Etkileri ${ }^{\S}$
}

\section{Inhibitory Effects of Aromaterapeutic Rose Essential Oil Against Bacterial Quorum Sensing and Biofilm Formation}

\author{
Elif Burcu Bali*®, Demet Erdönmez**®), Mustafa Yavuz***®, Ufuk Koca****® \\ * Gazi Üniversitesi, Sağlık Hizmetleri Meslek Yüksekokulu, Tıbbi Hizmetler ve Teknikler Bölümü, Tıbbi Laboratuvar Teknikleri Programı, Ankara, \\ Türkiye \\ ** Aksaray Üniversitesi, Fen-Edebiyat Fakültesi, Biyoloji Bölümü, Aksaray, Türkiye \\ *** İstanbul Medeniyet Üniversitesi, Fen-Edebiyat Fakültesi, İstanbul, Türkiye \\ **** Gazi Üniversitesi, Eczacılık Fakültesi, Farmakognozi Anabilim Dalı, Ankara, Türkiye
}

Atıf/Cite as: Bali EB, Erdönmez D, Yavuz M, Koca U. Aromaterapötik gül uçucu yağının bakteriyel quorum sensing ve biyofilm üretimine karşı inhibisyon etkileri. Turk Mikrobiyol Cemiy Derg. 2021;51(3):245-53

Alındığı tarih / Received: 17.10.2020 / 17. October.2020

Kabul tarihi / Accepted: 11.03.2021 / 11.March.2021

Yayın tarihi / Publication date: 07.09.2021 / 07.September.2021

\section{ORCiD Kayıtları}

E.B. Bali 0000-0002-5216-7588 D. Erdönmez 0000-0002-5331-2206

M. Yavuz 0000-0002-7797-8459

U. Koca 0000-0002-5216-7588

ukoca@gazi.edu.tr

\footnotetext{
${ }^{\S}$ Bu çalışmanın bir bölümü, III. Fitovizyon Doğal Yaşam ve Sağlık Ürünleri-Fitoterapi, Aromaterapi ve Kozmetikte Yenilikler Kongresi'nde (22-24 Kasım 2019, WOW Convention Center, Istanbul) sözlü bildiri olarak sunulmuştur.
}

öz

Amaç: Quorum sensing (QS), bakterilerin belli bir yoğunlukta hücreler arası sinyal molekülleri üretip bu sinyalleri algılayarak haberleşmelerini sağlayan kimyasal bir iletişim mekanizmasıdır. Bu çalışmada, ülkemizde aromaterapötik Rosa damascena Mill. (gül) uçucu yağının (AGUY) QS mekanizmasına ve insan patojeni mikroorganizmaların biyofilm üretimine karşı inhibisyon etkilerinin belirlenmesi amaçlanmıştır.

Yöntem: Araștırmada, AGUY'nin tüm mikroorganizmalara karșı minimum inhibisyon konsantrasyon (Mik) değerleri mikrodilüsyon yöntemiyle belirlenmiştir. AGUY'nin QS inhibisyon etkileri Chromobacterium violaceum ATCC 12472 (CV12472) biyosensör suşunda agar kuyucuk difüzyon ve viyolasin pigment üretimi yöntemleriyle saptanmıștır. Pseudomonas aeruginosa PAO1 suşunda ise bakterinin biyofilm üretimi, swarming (kayma) ve swimming (yüzme) hareket yetenekleri test edilmiștir.

Bulgular: AGUY'nin mikroorganizmalar üzerinde MiK değerleri \%0.0125-0.1 v/v aralığında belirlenmiştir. Çalışmada, AGUY'nin (sub-MiK:\%0.01 v/v), CV12472 suşunda viyolasin üretimini yüksek oranda (\%98.04 \pm 1.40 , p<0.05) azaltth̆ı saptanmısttr. AGUY (sub-MiK: \%0,2 v/v), PAO1 sussunda ise biyofilm oluşumunu güçü oranda

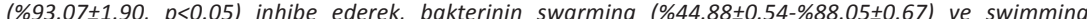
(\%47.60 $\pm 0.06-\% 85.48 \pm 0.10)$ hareket yeteneklerini doz artısına bağlı $(\% 0.0125-0.2 \mathrm{v} / \mathrm{v})$ engellediği bulunmuştur $(p<0.05)$. Çalışmada ayrıca, A GUY çoğu Gram pozitif $(\% 32.15 \pm 0.20-\% 52.40 \pm 1.30)$ ve Gram negatif $(\% 32.01 \pm 1.65$ $\% 61.00 \pm 0.84$ ) bakterilerinin biyofilm oluşumunu inhibe etmistir ( $p<0.05)$

Sonuc: Bu araștırma, AGUY'nin anti-mikrobiyal, anti-biyofilm ve anti-OS ajan olarak kullanımının gelecek için ümit verici potansiyelini göstermektedir. Araştırmada kullanılan AGUY'nin, insan patojeni mikroorganizmalarda biyofilm inhibisyon etkileri bildiğimiz kadarıyla bu çalışmada detaylı olarak ilk kez belirlenmiş olup, araştırma ülkemiz için AGUY üretiminin ve kullanımının son derece gerekli ve önemli olduğunu ve ülkemizde yetistirilen doğal ürünlere yönelik anti-QS ve anti-biofilm gibi biyolojik aktivite çalışmalarının daha detaylı araștırılması gerektiğini ortaya koymaktadır.

Anahtar kelimeler: Aromaterapötik gül uçucu yağı, quorum sensing, biyofilm

\section{ABSTRACT}

Objective: Quorum sensing (OS) is a chemical communication mechanism that allows bacteria to produce intercellular signal molecules in a certain density. In this study, it was aimed to detect the inhibition effects of aromaterapeutic Rosa damascena Mill. (Rose) essential oil (AREO) against QS mechanism and biofilm production of human pathogenic microorganisms.

Method: In the study, minimum inhibition concentration (MIC) values of AREO were determined by the microdilution method. The QS inhibition effects of the AREO were determined in Chromobacterium violaceum ATCC 12472 by agar well diffusion and violacein pigment production. The biofilm formation, swarm and swim motilities of Pseudomonas aeruginosa PAO1 strain were also tested.

Results: The MIC values of AREO were found to be in the range of $0.0125-0.1 \% \mathrm{v} / \mathrm{V}$. AREO (sub-MIC. $0.01 \% \mathrm{v} / \mathrm{v}$ ) significantly decreased $(98.04 \% \pm 1.40, p<0.05$ ) the violacein production. AREO (sub-MIC: $0.2 \% \mathrm{v} / \mathrm{v}$ ) strongly inhibited biofilm formation in PAO1 $(93.07 \% \pm 1.90, p<0.05)$, and significantly $(p<0.05)$ hindered the swarm $(44.88 \% \pm 0.54$ $88.05 \% \pm 0.67)$ and swim $(47.60 \% \pm 0.06-85.48 \% \pm 0.10)$ motilies of PAO1 according to the concentration ranges $(0.0125-0.2 \% \mathrm{v} / \mathrm{v})$. Additionally, AREO significantly $(p<0.05)$ inhibited the biofilm formation of gram-positive $(32.15 \% \pm 0.20-52.40 \% \pm 1.30)$ and gram-negative $(32.01 \% \pm 1.65-61.00 \% \pm 0.84)$ acteria.

Conclusion: This study reveals the promising potential of AREO used as anti-microbial, anti-biofilm and anti-QS agents in the future. To the best of our knowledge, the biofilm inhibition effects of AREO in human pathogenic microorganisms have been studied in detail for the first time, and this work clearly reveals that the production and use of AREO is extremely necessary and important for Turkey. Therefore, the anti-QS and anti-biofilm activity research about natural compounds should be worked in detail.

Keywords: Aromaterapeutic rose essential oil, quorum sensing, biofilm 


\section{Giriş̧}

Gül (Rosa species) dünyada 200'den fazla türü ve 18.000 çeşidi ile Rosaceae familyasına ait tıbbi ve peyzaj bitkisidir. Rosa damascena Mill. (Şam gülü) koku, lezzet ve tıbbi özelliklerinden dolayı özellikle Türkiye ve Bulgaristan'da yüksek kalitede yetiştirilmektedir ${ }^{(1,2)}$. Tüm dünyada, gül uçucu yağının Bulgaristan'dan sonra ikinci üreticisi Türkiye olup, Isparta ekonomik olarak en önemli üretici merkezidir. Isparta'da 36'dan fazla farklı çeşidi bulunan gül ve farklı ürünleri gıda, kozmetik ve tıbbi alanlarda kullanılmaktadır $^{(3)}$. Gül yağı geleneksel tıpta stres, ağrı, üzüntü, depresyon, gerginlik, menstrual bozukluklar, jinekolojik hastalıklar, cinsel işlev bozukluğu gibi durumlarda, yara iyileşmesinde, sindirim sistemi hastalıklarında ve aromaterapide kalp ve solunum hastalıkları gibi birçok hastalığın tedavisinde kullanılmaktadır. Ayrıca birçok modern parfüm ve kozmetik ürünlerinin temel bileşeni olarak parfüm ve kozmetik endüstrisinde yaygın kullanıma sahiptir ${ }^{(4-7)}$. Yapılan çalışmalarda, gül yağının temel bileşenlerini feniletil alkol, sitrenellol, nonadekan, geraniol, transgeraniol, etanol, nerol, heneikosan ve kaempferol türevlerinin oluşturduğu belirlenmiştir ${ }^{(8,9)}$. Ayrıca geleneksel ve modern tıpta yaygın olarak kullanılan gül uçucu yağı, yüksek frekansı ve biyoaktivitesinden sorumlu farklı monoterpenoidler ve seskiterpenoidlerin son derece zengin bir kaynağını oluşturmaktadır ${ }^{(10)}$.

Gül yağı ile ilgili yapılmış olan çalışmalarda, bu yağın antioksidan, laksatif, anksiyolitik, anti-spazmodik, anti-tussif, anti-depresan, anti-diyabetik, anti-kanser, anti-kolvülsan, anti-mikrobiyal, anti-septik, anti-HIV gibi birçok farmakolojik özelliği ve güncel bir in vivo araştırmada ise gül yağından hazırlanan gargara ve jelin analjezik ve anti-inflamatuvar özelliklere de sahip olduğu gösterilmiştir ${ }^{(1,9,11,12)}$. Bu çalışmalarla birlikte, son on yıldır yapılmış olan araştırmaların içinde gül yağının bakteriyel enfeksiyonları önlemede bakteriyel iletişim mekanizmasını engellediğini gösteren çalışmalar da mevcuttur ${ }^{(13-15)}$.

Bakterilerde hücre-hücre iletişimi sinyal molekülleri aracılığıyla sağlanmaktadır. Bakteri sayısı arttıkça hücre dışına salınan sinyal moleküllerinin sayısı da artmakta ve bu artış algılanabilmektedir. Bakterilerin, belli bir yoğunlukta bu sinyalleri algılayarak çeşitli davranışlar sergilemesi "çoğunluğu algılama" veya "Quorum-sensing (QS)" olarak adlandırılmaktadır. QS mekanizması ile bakteriler kendi çevresini izlemekte, popülasyon yoğunluğu hakkında bilgi almakta ve bu bilgileri yeri gelince gen ifadesini düzenlemede kullanmaktadırlar. QS, global bir düzenleyici olarak bakterilere gen transfer yeteneğini arttırmakta ve bakterilerde biyofilm oluşumu, pilus biyogenezi, çeşitli çoklu virülans faktörlerin üretimi veya konak hücreleri parçalayan enzimlerin sentezi, antibiyotik direnç gelişimi gibi kritik bazı fizyolojik fonksiyonların kontrolünü sağlamaktadır ${ }^{(16-18)}$.

Patojenik bakterilerin patojenite ve virülans faktörlerinin üretimini QS mekanizmasıyla düzenlediklerinin keşfi, bu mekanizmayı enfeksiyon hastalıklarının tedavisi için cazip bir hedef durumuna getirmiştir. Bakterileri öldürmek yerine patogenezi hedef almak, sentetiklerin yanı sıra doğal bileşikleri de içeren bakteriyel iletişim inhibitörleri kullanarak QS mekanizmasını bloke etmek, bakteriyel direnç sorunları ve bakteriyel enfeksiyonlarla savaşmada büyük bir umut kaynağı olarak görülmektedir ${ }^{(19)}$. QS mekanizmasını bloke eden doğal bir bileşik olarak rapor edilen gül uçucu yağının içeriğinde monoterpen alkoller (sitronellol, geraniol, nerol) ve parafinik hidrokarbonlar (nonadesan, 9-nonadesen) yüksek oranda bulunan aktif bileşenler olup, bu bileşenlerin QS mekanizmasının inhibisyonunda önemli bir rolü olabilir ${ }^{(14)}$.

Bu çalışmada, Rosa damascena Mill. (gül) yağının Chromobacterium violaceum ATCC 12472 ve Pseudomonas aeruginosa PAO1 biyosensör suşlarına karşı anti-QS ve 14 adet insan patojeni mikroorganizmaya karşı anti-biyofilm etkilerinin belirlenmesi amaçlanmıştır. Literatürde gül yağının farmakolojik özelliklerini gösteren birçok çalışma olmasına rağmen, bildiğimiz kadarıyla bu çalışma bu yağın insanlarda ciddi enfeksiyonlara neden olan ve çoklu direnç gösteren mikroorganizmalara karşı antimikrobiyal etkisine ilaveten, QS ve QS ile ilişkili olan biyofilm inhibisyon etkilerini gösteren ilk detaylı araştırmadır. 


\section{GEREÇ ve YÖNTEM}

\section{Aromaterapötik gül uçucu yağı ve saklama koşulları:}

$\mathrm{Bu}$ araştırmada kullanılan aromaterapötik gül uçucu yağı (Rosense) ticari olarak satın alınmış olup, deneylerde kullanılmak üzere $+4^{\circ} \mathrm{C}^{\prime}$ de korunmuştur.

Mikroorganizmalar ve kültür koşulları: Çalışmada, aromaterapötik gül uçucu yağının anti-mikrobiyal ve anti-biyofilm etkilerini belirlemek için sekiz adet Gam negatif bakteri; Pseudomonas aeruginosa (ATCC 27853), Escherichia coli (ATCC 25922), Acinetobacter baumannii (ATCC 19606), Klebsiella pneumoniae (ATCC 700603), Klebsiella oxytoca (ATCC 43165), Proteus mirabilis (ATCC 7002), Salmonella Typhimurium (ATCC 14074), Serratia marcescens (ATCC 27117); 5 adet gram pozitif bakteri: Enterococcus faecalis (ATCC 29212), Micrococcus luteus (ATCC 7468), Bacillus cereus (ATCC 6633), Staphylococcus epidermidis wt ve Staphylococcus aureus (ATCC 29213) ve bir adet maya; Candida albicans (ATCC10231) kullanılmıştır. Bakteri suşları $37^{\circ} \mathrm{C}^{\prime} \mathrm{de}$ 24-48 saat Brain Heart Infusion (BHI) broth ve agar (BHA) besiyerlerinde, C. albicans fungusu ise Sabouraud Dextrose Broth (SDB) ve agar (SDA) besiyerlerinde $30^{\circ} \mathrm{C}^{\prime}$ de $48-72$ saat inkübasyona bırakılarak üretilmiştir. Aromaterapötik gül uçucu yağının anti-QS etkisinin belirlenmesinde ise Chromobacterium violaceum ATCC 12472 (CV12472) ve $P$. aeruginosa $\mathrm{PAO} 1$ suşları kullanılmıştır. CV12472 suşu $30^{\circ} \mathrm{C}^{\prime}$ de, $P$. aeruginosa PAO1 ise $37^{\circ} \mathrm{C}$ 'de Luria Bertani (LB) broth veya LB agarda 24-48 saat üretilmiştir. Mikroorganizmaların kültür bulanıklıkları Mc Farland $0.5^{\prime} \mathrm{e}\left(10^{8} \mathrm{cfu} / \mathrm{ml}\right)$ ayarlanarak tüm deneyler yapılmıştır.

Minimum inhibisyon konsantrasyonu (MiK) yöntemi: Çalışmada, farklı konsantrasyonlardaki aromaterapötik gül uçucu yağının minimum inhibisyon konsantrasyonun (МіK) belirlenmesi için mikrodilüsyon yöntemi kullanılmıştır(20). Yağ, steril 96 kuyucuklu mikroplakalara $100 \mu \mathrm{l}$ Brain Heart Infusion (BHI) Broth ile $1 / 2$ seyreltilerek konulmuş ve mikroorganizmalar her bir kuyucuğa $5 \mu \mathrm{l}$ mikroorganizma $+95 \mu \mathrm{BHI}$ olarak ilave edilmiştir. Kuyucuklardaki son hacim 200 $\mu \mathrm{l}$ olarak ayarlanarak $37^{\circ} \mathrm{C}^{\prime}$ de 24 saat inkübasyona bırakılmıştır. İnkübasyon sonrası mikroplakalar mikroplate okuyucuda (Chromate 4300, ABD) kontrole göre 600 nm'de ölçülmüştür. Deneyde pozitif kontrol için gentamisin ve vankomisin antibiyotikleri, amfoterisin B antifungal ajanı kullanılmıştır.

\section{Aromaterapötik Gül Yağının QS İnhibisyon Etkileri}

Agar kuyucuk difüzyon testi:_10 mL Luria Bertani (LB) agar besiyerine, $100 \mu \mathrm{L}$ CV12472 suşu eklenmiştir. Katılaşan yumuşak Luria Bertani (LB) agar besiyerine steril delgeç yardımıyla $6 \mathrm{~mm}$ çapında açılan kuyucuklara DMSO ile 1/8 dilue edilerek hazırlanmış $20 \mu$ l gül yağı, \%0.01 v/v sub-Mik konsantrasyonda bırakılmış ve bakteri $30^{\circ} \mathrm{C}$ etüvde $24-48$ saat inkübe edilmiştir. İnkübasyon sonucunda, kuyucukların etrafinda oluşan opak zonlar QS inhibisyon etkisi olarak değerlendirilip zonlar milimetrik olarak ölçülmüştür ${ }^{(21,22) \text {. }}$

Viyolasin pigment üretiminin inhibisyon testi: SIVI kültürden viyolasin pigment üretiminin inhibisyon testi, viyolasin pigment ekstraksiyonu yöntemine göre yapılmıştır ${ }^{(23)}$. On beş saatlik CV12472 suşu 20 ml Luria Bertani (LB) besiyerindeki taze kültürden 10 $\mu \mathrm{L}$ alınarak $1 \mathrm{~mL}$ LB besiyerine inoküle edilmiştir. Kontrol grubuna yalnızca bakteri, test grubuna ise $\% 0.01 \mathrm{v} / \mathrm{v}$ sub-Mik konsantrasyon olacak şekilde 20 $\mu l$ yağ eklenerek, tüpler $30^{\circ} \mathrm{C}^{\prime}$ de $24-48$ saat çalkalamalı etüvde inkübasyona bırakılmıştır. Sonrasında her bir tüpten $200 \mu \mathrm{l}$ kültür alınıp, $1.5 \mathrm{ml}$ ependorf tüpe aktarılmıştır. Hücrenin parçalanması için üzerine $200 \mu \mathrm{l} \% 10$ SDS çözeltisi eklenip, tüpler 5 dakika boyunca vortekslendikten sonra 5 dakika oda sıcaklığında bekletilmiştir. Viyolasin pigmenti izolasyonu için suyla doyurulmuş olan bütanol $900 \mu \mathrm{l}(50 \mathrm{ml}$ n-bütanol $+10 \mathrm{ml}$ distile su) olarak tüpe eklenmiş ve 5 saniye vortekslenmiştir. Daha sonra 10000 rpm'de 5 dakika boyunca santrifüj edilmiştir. Üstteki faz küvete aktarılarak 585 nanometrede Genesys ${ }^{\mathrm{TM}} 10 \mathrm{~S}$ UV-Vis spektrofotometrede (Thermo Fisher Scientific) okunup \% viyolasin inhibisyon miktarı hesaplanmıştır.

Swarming ve swimming (Kayma ve yüzme) hareketi inhibisyon testi: Aromaterapötik gül uçucu yağının $P$. aeruginosa PAO1 suşunun swimming (yüzme) ve swarming (kayma) hareketlerine karşı inhibisyon 
etkileri literatüre uygun olarak test edilmiştir ${ }^{(24)}$. Swimming testi için, bir gecelik aktif PAO1 $\left(10^{8} \mathrm{cfu} / \mathrm{ml}\right)$ kültürden $3 \mu \mathrm{l}$ alınarak \%0.0125-\%0.2 (v/v) sub-Mik konsantrasyonlarda gül yağı içeren swimming agar (\% 1 tripton, \% $0.5 \mathrm{NaCl}$ ve \% 0.3 agar) petrilerine nokta ekim yapılmıştır. Swarming testi için ise, aynı koşullardaki bir gecelik aktif PAO1 kültüründen $5 \mu \mathrm{l}$ alınarak aynı konsantrasyonlarda yağ içeren swarming agar (\%1 pepton, \%0.5 NaCl, \% 0.5 D-glikoz ve $\% 0.5$ agar) petrilerine nokta ekim yapılımıştır. Petriler ters çevrilmeden $37^{\circ} \mathrm{C}$ 'de 16 saat inkübasyona bırakılmış ve inkübasyon sonunda koloni çapları milimetrik olarak ölçülmüştür.

Aromaterapötik gül uçucu yağının biyofilm inhibisyon etkileri: Aromaterapötik gül uçucu yağının patojen mikroorganizmalar için inhibisyon etkileri literatüre uygun olarak belirlenmiştir(25). Yirmi dört kuyucuklu polistren plaklara kontrol ve \%0.2-\%0.0125 (v/v sub-Mik konsantrasyonlarda hazırlanmış gül yağı eklenmiştir. Uygun besiyerine $\left(10^{8} \mathrm{cfu} / \mathrm{ml}\right)$ ekilmiş mikroorganizmalar 200 rpm'de çalkalamalı etüvde $30^{\circ} \mathrm{C}$ veya $37^{\circ} \mathrm{C}$ 'de 48 saat inkübe edilmiştir. İnkübasyonun ardından 24 kuyucuklu polistren plakların her bir kuyucuğuna $900 \mu \mathrm{l}$ besiyeri $+100 \mu \mathrm{l}$ mikroorganizma eklenmiştir. $30^{\circ} \mathrm{C}$ veya $37^{\circ} \mathrm{C}$ 'de kültürler yine 48 saat inkübe edilmiştir. Kültürler üretildikten sonra plaklardan besiyerleri alınarak her bir kuyucuk üç kez $1 \mathrm{X}$ PBS tamponu ile yıkanmıştır. Daha sonra bu plaklar $65^{\circ} \mathrm{C}^{\prime}$ ye ayarlanan etüvde kurutularak, plaklar \%1 kristal viyole çözeltisi ile iki dakika süreyle boyanmıştır. Sonrasında kuyucuklar distile su ile üç kez yıkanmış ve oda sıcaklığında kurumaya bırakılmıştır. Yüzde 30'luk asetik asit çözeltisi ile çözülen kuyucuklardaki kristal viyole çözeltisi 595 nm spektrofotometrede kontrole karşı ölçülmüştür.

İstatiksel analizler: Çalışmada uygulanılan tüm testler en az üç yine yapılmış olup, deney sonuçları, üç tekrarın ortalama \pm standart sapması (SD) olarak belirtilmiştir. Analizler için SPSS (Program 11.0) paketi kullanılarak, veriler tek yönlü varyans analizine (ANOVA) tabi tutulmuştur. Kontrole göre ${ }^{*} p<0.05$ değeri istatistiksel olarak anlamlı kabul edilmiştir.

\section{BULGULAR}

Minimum inhibisyon konsantrasyon (MiK) sonuçları: Araştırmada, aromaterapötik gül uçucu yağının biyosensör suşlar ve patojen mikroorganizmalara karşı QS ve biyofilm inhibisyon etkilerini belirlemek için öncelikle yağın mikroorganizmalar üzerindeki minimum inhibisyon konsantrasyon değerleri saptanmıştır (Tablo 1). Aromaterapötik yağın tüm mikroorganizmalar üzerinde MiK değerleri \%0.0125-0.4 v/v aralığında olduğu belirlenmiştir. Çalışmada, pozitif kontrol olarak Gram pozitif ve negatif bakteriler için gentamisin ve vankomisin antibiyotikleri,

Tablo 1. Aromaterapötik gül yağının patojen mikroorganizmalar ve biyosensör suşlara karşı Mik değerleri.

\begin{tabular}{|c|c|c|c|c|}
\hline $\begin{array}{l}\text { Patojen Mikroorganizmalar ve Biyosensör Suşlar/ } \\
\text { MiK Değerleri }\end{array}$ & $\begin{array}{l}\text { Gül Yağı } \\
\text { (v/v) }\end{array}$ & $\begin{array}{l}\text { Gentamisin } \\
(\mu \mathrm{g} / \mathrm{ml})\end{array}$ & $\begin{array}{l}\text { Vankomisin } \\
(\mu \mathrm{g} / \mathrm{ml})\end{array}$ & $\begin{array}{l}\text { Amfoterisin B } \\
(\mu \mathrm{g} / \mathrm{ml})\end{array}$ \\
\hline Pseudomonas aeruginosa (ATCC 27853) & 0.1 & 8 & - & - \\
\hline Escherichia coli (ATCC 25922) & 0.1 & 0.25 & - & - \\
\hline Acinetobacter baumannii (ATCC 19606) & 0.05 & 16 & - & - \\
\hline Klebsiella pneumoniae (ATCC 700603) & 0.0125 & 0.5 & - & - \\
\hline Klebsiella oxytoca (ATCC 43165) & 0.025 & 0.5 & - & - \\
\hline Proteus mirabilis (ATCC 7002) & 0.0125 & 1 & - & - \\
\hline Salmonella Typhimurium (ATCC 14074) & 0.1 & 1 & - & - \\
\hline Serratia marcescens (ATCC 27117) & 0.1 & 0.5 & - & - \\
\hline Enterococcus faecalis (ATCC 29212) & 0.1 & - & 16 & - \\
\hline Micrococcus luteus (ATCC 7468) & 0.05 & - & 16 & - \\
\hline Bacillus cereus (ATCC 6633) & 0.05 & - & 1 & - \\
\hline Staphylococcus epidermidis wt & 0.05 & - & 4 & - \\
\hline Staphylococcus aureus (ATCC 29213) & 0.1 & - & 1 & - \\
\hline Candida albicans (ATCC10231) & 0.05 & - & - & 1 \\
\hline Pseudomonas aeruginosa PA01 & 0.4 & 8 & - & - \\
\hline Chromobacterium violaceum (ATCC 12472) & 0.025 & 16 & - & - \\
\hline
\end{tabular}




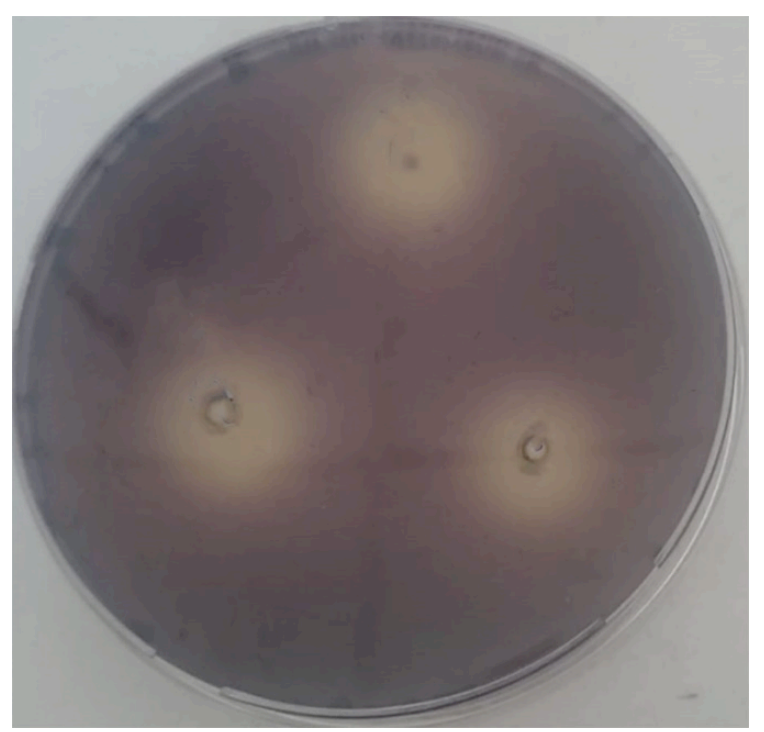

Şekil 1. Aromaterapötik gül uçucu yağının Chromobacterium violaceum 12.472 suşunda oluşturduğu üç tekrarlı viyolasin inhibisyon zonları (mm).

C. albicans mayası için de antifungal olarak amfoterisin B kullanılmıştır. Aromaterapötik gül yağına en duyarlı patojenlerin $\% 0.0125$ ve $\% 0.025$ MiK değerleriyle $K$. pneumoniae, $K$. oxytoca, $C$. violaceum ve P. mirabilis, türleri olduğu saptanmıştır (Tablo 1 ). Aromaterapötik gül yağına daha yüksek Mik değeri (\%0.4 ve \%0.1) saptanan türlerin ise Pseudomonas,
E. coli, S. Typhimurium, S. marcescens, E. fecalis ve S. aureus türleri olduğu belirlenmiştir (Tablo 1 ). Gül yağının QS ve biyofilm inhibisyon etkilerinin belirlenmesi için MiK altındaki (sub-MiK) dozları mikroorganizmalar üzerine uygulanmıştır.

Aromaterapötik Gül Uçucu Yağının Pseudomonas aeruginosa PAO1 Suşu Üzerine QS İnhibisyon Etkileri Swarming ve swimming hareketi ilnhibisyonu: Pseudomonas aeruginosa PAO1 suşunun swarmming (kayma) ve swimming (yüzme) hareketleri QS mekanizmasıyla düzenlenmekte olup, aromaterapötik gül uçucu yağının swarming ve swimming hareketi inhibisyon sonuçları Tablo 2 ve Tablo 3'te gösterilmiştir. PAO1 için aromaterapötik gül yağının sub-Mik dozlarındaki (\%0.0125-\%0.2) swarming ve swimming hareketi inhibisyon etkileri bakılmış olup, doz artışına bağlı olarak gül yağının bakterinin swarming ve swimming hareketlerini engelleyerek, inhibisyon oranını anlamlı bir şeklide $(p<0.05) \% 43.51 \pm 0.54$ 'ten $88.050 \pm 0.67$ 'ye yükselttiği ve aynı şekilde swimming hareketindeki inhibisyon oranının da \%47.60 \pm 0.06 'dan $\% 85.48 \pm 0.10$ 'a anlamlı olarak $(\mathrm{p}<0.05)$ artttığı saptanmıştır (Tablo 2 ve Tablo 3). Çalışmada, PAO1 suşunun swarming ve swimming hareketlerindeki inhibis-

Tablo 2. Aromaterapötik gül uçucu yağının Pseudomonas aeruginosa PAO1 biyosensör suşunun swarm (kayma) hareketi üzerinde inhibisyon etkisi.

\begin{tabular}{lcc}
\hline $\begin{array}{l}\text { Gül Yağı } \\
\text { (v/v) }\end{array}$ & $\begin{array}{c}\text { Swarming Hareketi } \\
\text { Zon Çapı (mm) }\end{array}$ & $\begin{array}{c}\text { Swarming Hareketi } \\
\text { Inhibisyonu (\%) }\end{array}$ \\
\hline Kontrol & $62.25 \pm 1.75$ & 0 \\
0.0125 & $35.16 \pm 0.92^{*}$ & $43.51 \pm 0.54^{*}$ \\
0.025 & $32.62 \pm 0.74^{*}$ & $47.60 \pm 0.58^{*}$ \\
0.05 & $31.41 \pm 1.47^{*}$ & $50.54 \pm 0.16^{*}$ \\
0.1 & $15.12 \pm 1.03^{*}$ & $75.71 \pm 0.41^{*}$ \\
0.2 & $7.50 \pm 0.57^{*}$ & $88.05 \pm 0.67^{*}$ \\
\hline
\end{tabular}

CFU: Koloni oluşturan unite (Colony Forming Unit), ${ }^{*} p<0.05$

Tablo 3. Aromaterapötik gül uçucu yağının Pseudomonas aeruginosa PAO1 biyosensör suşunun swim (yüzme) hareketi üzerinde inhibisyon etkisi.

\begin{tabular}{lcc}
\hline $\begin{array}{l}\text { Gül Yağı } \\
(\mathbf{v} / \mathbf{v})\end{array}$ & $\begin{array}{c}\text { Swarming Hareketi } \\
\text { Zon Çapı }(\mathbf{m m})\end{array}$ & $\begin{array}{c}\text { Swarming Hareketi } \\
\text { İnhibisyonu (\%) }\end{array}$ \\
\hline Kontrol & $69.06 \pm 0.02$ & 0 \\
0.0125 & $36.13 \pm 0.08^{*}$ & $47.60 \pm 0.06^{*}$ \\
0.025 & $35.42 \pm 0.20^{*}$ & $48.63 \pm 0.07^{*}$ \\
0.05 & $28.24 \pm 0.04^{*}$ & $59.04 \pm 0.02^{*}$ \\
0.1 & $17.84 \pm 0.06^{*}$ & $74.12 \pm 0.03^{*}$ \\
0.2 & $10.01 \pm 0.25^{*}$ & $85.48 \pm 0.10^{*}$ \\
\hline
\end{tabular}

CFU: Koloni oluşturan unite (Colony Forming Unit), ${ }^{*} p<0.05$ 
Tablo 4. Aromaterapötik gül yağının patojen mikroorganizmalara karşı \% biyofilm inhibisyon etkileri $\left({ }^{*} p<0.05\right)$.

\begin{tabular}{lc}
\hline Insan Patojeni & $\begin{array}{c}\text { Biyofilm } \\
\text { Mikroorganizmalar }\end{array}$ \\
\hline Inhibisyonu (\%) \\
\hline Pseudomonas aeruginosa PA01 & $93.07 \pm 1.90^{*}$ \\
Pseudomonas aeruginosa (ATCC 27853) & $60.89 \pm 0.84^{*}$ \\
Escherichia coli (ATCC 25922) & $50.64 \pm 1.42^{*}$ \\
Acinetobacter baumannii (ATCC 19606) & $2.88 \pm 0.80$ \\
Klebsiella pneumoniae (ATCC 700603) & $2.44 \pm 0.53$ \\
Klebsiella oxytoca (ATCC 43165) & $3.01 \pm 0.21$ \\
Proteus mirabilis (ATCC 7002) & $46.73 \pm 1.26^{*}$ \\
Salmonella Typhimurium (ATCC 14074) & - \\
Serratia marcescens (ATCC 27117) & $32.01 \pm 1.65^{*}$ \\
Enterococcus faecalis (ATCC 29212) & $5.85 \pm 0.55$ \\
Micrococcus luteus (ATCC 7468) & $52.40 \pm 1.30^{*}$ \\
Bacillus cereus (ATCC 6633) & $10.74 \pm 0.42$ \\
Staphylococcus epidermidis wt & $50.36 \pm 0.52^{*}$ \\
Staphylococcus aureus (ATCC 29213) & $32.15 \pm 0.20^{*}$ \\
Candida albicans (ATCC10231) & $48.31 \pm 2.05^{*}$ \\
\hline
\end{tabular}

yonlarının artışına bağlı olarak, hareket yetenekleri kısıtlandığından oluşan zon çapları da aromaterapötik gül yağının doz artışına bağlı olarak azalmıştır. Gül yağı sub-Mik dozlarda PAO1 suşunun hareket yeteneklerini inhibe etmiş $(p<0.05)$, ama bakteri hücre canlılı̆ı̆ı değiştirmemiştir (Tablo 2 ve Tablo 3 ).

Aromaterapötik gül uçucu yağının patojen mikroorganizmalara karşı biyofilm inhibisyon etkileri: Çalışmada, sub-Mik dozlardaki aromaterapötik gül uçucu yağının K. oxytoca, E. faecalis, K. pneumoniae, A. baumannii, $S$. Typhimurium ve $B$. cereus bakterilerine karşı anlamlı bir etkisi saptanamamıştır ( $p>0.05)$ (Tablo 3). Buna karşı, gül yağının $P$. aeruginosa, E. coli, P. mirabilis, S. Typhimurium, S. marcescens, $M$. luteus, $S$. epidermidis wt ve $S$. aureus bakterilerinde biyofilm üretimini anlamlı oranda $(p<0.05)$ inhibe ettiği (\%32.15 $\pm 0.20-\% 60.89 \pm 0.84)$ saptanmıştır (Tablo 3). Gül yağının Gram pozitif bakterilerde $\% 32.15 \pm 0.20-\% 52.40 \pm 1.30$, Gram negatif bakterilerde ve C. albicans (ATCC10231) mayasında ise $\% 32.01 \pm 1.65-\% 60.89 \pm 0.84$ aralığında anlamlı olarak $(p<0.05)$ biyofilm inhibisyon etkisi belirlenmiştir (Tablo 4). Biyofilm üretimi QS mekanizması ile gerçekleşen $P$. aeruginosa PAO1 suşunda ise gül yağının en yüksek biyofilm inhibisyon etkiye $(\% 93.07 \pm 1.90$; $p<0.05)$ sahip olduğu saptanmıştır.

\section{TARTIŞMA}

Aromaterapide çoğunlukla kaygı, menstrual ve ame- liyat sonrası ağrı giderimi, hastalarda rahatlık ve memnuniyet duygularııı artışının sağlanması için uygulanan gül uçucu yağı, içeriğindeki ana komponentler olan geraniol ve sitronellol bileşikleri sayesinde çoklu biyo-farmakolojik aktivite gösteren yüksek frekanslı bir yağdır ${ }^{(2,11)}$. Bu yağ geniş spektrumlu antibakteriyel ve antifungal özelliklere sahiptir(26-28). Ulusoy ve ark. ${ }^{(29)}$ gülün absolut ve uçucu yağının yüksek oranda fenolik madde içerdiğini ve uçucu yağın absolut yağdan daha güçlü antibakteriyel aktivite gösterdiğini MiK yönteminde saptamışlardır. Gül yağını \%4 (v/v)'ten \%0.03 (v/v) kadar yarı yarıya dilue etmişler ve uçucu yağın E. coli ATCC 25922, P. aeruginosa ATCC 27853 ve C. violaceum ATCC 12472 için Mik değerlerinin \%0.25 v/v ile >\%4 v/v arasında olduğunu belirlemişlerdir. Bizim çalışmamızda ise, aynı bakteri suşlarına karşı gül yağının MiK değerleri \%0.025 v/v ile \%0.1 v/v arasında belirlenmiş olup, bu çalışmaya kıyasla gül yağının bakterilere karşı daha yüksek aktivite gösterdiği saptanmıştır. Bunun nedeni çalışmada kullanılan gül yağının içeriğindeki etken bileşikler olabilir.

Gül (R. damascena Mill.) yağının en önemli bileşenlerini sitronellol, geraniol, nerol ve linalool gibi monoterpenik alkoller, nonadesan, heneikosan, 9-nonadesen ve eikosan gibi uzun zincirli hidrokarbonlar, öjenol gibi fenoller, geranil asetat ve sitronellil asetat gibi ester ve aldehitler ile metil öjenol gibi oksit ve eterler oluşturmaktadır ${ }^{(14,29,30)}$. Çalışmamızda, yağın gram pozitif ve gram negatif bakteriler üzerine antibakteriyel etkilerinin içeriğindeki sitronellol, geraniol ve nerol gibi ana bileşenlerle ilişkili olabileceği düşünülmektedir ${ }^{(29)}$. Yi ve ark. ${ }^{(31)}$ kimyasal kompozisyonları değişiklik gösteren ve çeşitli türlerden elde edilen gül uçucu yağlarının antimikrobiyal etkinliklerini araştırmış ve bu etkinlikleri çalışmamızdan farklı konsantrasyonlarda $(\mathrm{mg} / \mathrm{ml})$ saptamışlardır. Gül uçucu yağlarının antimikrobiyal etkilerine neden olan ana bileşikleri linalool, fenetil alkol, $\beta$-sitronellol, geraniol, öjenol ve metil öjenol olarak belirlemişlerdir. Araştırmada kullanılan gül uçucu yağlarının elde ediliş yöntemleri ve içerik farklıılıklarından dolayı, yağların antimikrobiyal aktivitelerinden sorumlu ana bileşenleri değişkenlik göstermektedir. 
Quorum sensing (QS), kronik bakteriyel hastalıklar gibi çeşitli insan hastalıklarında mikrobiyal patojenite ve antibiyotik direncinde önemli rol oynar. QS inhibisyonu, sistemik ve lokal enfeksiyonlarda patojeniteyi, antibiyotik direncini ve biyofilm oluşumunu azaltabilir $^{(13)}$. Zhang ve ark.'nın ${ }^{(15)}$ bu konuyla ilgili araştırmasında, Rosa rugosa çayının polifenol ekstraktının anti-biyofilm ve QS inhibitör potansiyeli belirlenmiş, ekstraktın konsantrasyon artışına bağlı olarak C. violaceum 026 suşunun viyolasin pigment üretimini \%87.56 azalttığı, P. aeruginosa PAO1 suşunda ise swarming (kayma) hareketini (\%78.03) ve biyofilm oluşumunu (\%72.90) inhibe ettiği belirlenmiştir. Daha önceden yapılmış diğer bir çalışmada ise aralarında gül yağını da içeren çeşitli uçucu yağların, bakteri büyümesi ve QS üzerine etkileri araştırılmış ve test edilen yağlar arasında gül yağının da en güçlü QS inhibitörlerinden biri olduğu saptanmıştır ${ }^{(13)}$. Mevcut çalışma sonuçlarımız, gül yağının QS ve biyofilm etki potansiyelleri açısından bu çalışmalarla uyumluluk göstermekte olup, çalışmamızda kullanılan aromaterapötik gül yağı doza bağlı olarak CV12472 ve PAO1 suşlarının QS mekanizmasını ve PAO1 suşunun biyofilm oluşumunu mevcut çalışmalardaki gibi güçlü oranda inhibe ettiği belirlenmiştir.

Gül uçucu yağının QS mekanizmasını inhibe etme potansiyeli farklı biyosensör ve klinik suşlarda da çalışılmıştır ${ }^{(14)}$. Çalışmada, \%0.0025 (v/v) konsantrasyondaki gül yağının $P$. aeruginosa klinik izolatlarının biyofilm oluşumunu istatiksel olarak önemli oranda (\%53) azalttığı fakat PAO1 suşunun biyofilm oluşumunda anlamlı bir azalma (\%12) olmadığı rapor edilmiştir. Buna ek olarak, bu dozdaki yağın $C$. violaceum 026, C. violaceum VIR07 ve C. violaceum 12472 (CV12472) suşlarında sırasıyla \%80, \%70 ve \%43 oranlarında viyolasin pigment üretimini azalttığı saptanmıştır. Bu sonuçlardan farklı olarak bizim çalışmamızda ise \%0.01 v/v dozdaki aromaterapötik olarak kullanılan gül uçucu yağı CV12472 suşunun viyolasin

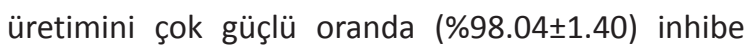
etmiştir. Yüzde $0.2 \mathrm{v} / \mathrm{v}$ dozdaki aromaterapötik gül uçucu yağı ise PAO1 biyofilm üretimini istatistiksel olarak anlamlı olarak $(p<0.05)$ ve çok yüksek oranda (\%93.07士1.90) azaltmıştır. Çalışmamızda kullanılan aromaterapötik gül uçucu yağının suşlar üzerindeki
sub-Mik dozları mevcut çalışmadan daha yüksektir. Buna bağlı olarak da aromaterapötik gül yağının antiQS ve anti-biyofilm potansiyelleri diğer çalışmalardan farklılık göstermiştir.

Sonuç olarak, çalışma sonuçlarımız aromaterapötik gül uçucu yağının güçlü $Q S$ ve biyofilm inhibisyon potansiyelini göstermektedir. Çalışmamızda kullanılan aromaterapötik yağın insan patojeni mikroorganizmalardaki biyofilm inhibisyon etkileri bildiğimiz kadarıyla detaylı olarak ilk kez belirlenmiştir. Gül uçucu yağının çeşitli farmakolojik özellikleri ve antibiyotiklere alternatif olarak direnç gelişimine neden olmadan enfeksiyonları durdurma potansiyelleri, çalışmadan elde edilen bu sonuçlarla daha güçlü ortaya çıkarılmıştır. Enfeksiyonlara karşı oluşan direncin önlenmesi için alternatif doğal bileşiklere karşı olan arayış her zaman devam etmektedir. Aromaterapötik gül uçucu yağı gibi etkili ve doğal bileşenlerin yan etkilerinin sentetik ilaçlara göre daha az oluşu, çoklu biyolojik aktivitelere sahip olmaları gibi nedenler bu arayışı sürdürmemizin ne denli gerekli ve önemli olduğunu net olarak ortaya koymaktadır. Yağın farmakolojik özelliklerinde içeriğindeki sitronellol, geraniol ve nerol gibi etken bileşikler önemli olup, konuyla ilgili olarak bu bileşiklerin bakteriyel QS ve biyofilm mekanizmalarını nasıl bloke ettiğini gösteren ileri moleküler çalışmalar yapılması önerilmektedir.

Çıkar Çatışması: Yazarlar bu makale ile ilgili herhangi bir çıkar çatışması bildirmemişlerdir.

Conflict of Interest: No conflict of interest was declared by the authors.

\section{KAYNAKLAR}

1. Nayebi N, Khalili N, Kamalinejad M, Emtiazy M. A systematic review of the efficacy and safety of Rosa damascena Mill. with an overview on its phytopharmacological properties. Complement Ther Med. 2017;34:129-40. https://doi.org/10.1016/j.ctim.2017.08.014

2. Akram M, Riaz M, Munir N, et al. Chemical constituents, experimental and clinical pharmacology of Rosa damascena: a literature review. J Pharm Pharmacol. 
2020;72(2):161-74.

https://doi.org/10.1111/jphp.13185

3. TarbiatS, Türütoğlu AS, Ekingen M. Acetylcholinesterase inhibitory potential and antioxidant activities of five cultivars of Rosa damascena Mill. from Isparta, Turkey. Curr Top Nutraceutical Res. 2020;18(4):354-359. https://doi.org/10.37290/ctnr2641-452X.18:354-359

4. Toluei Z, Hosseini Tafreshi SA, Arefi Torkabadi M. Comparative chemical composition analysis of essential oils in different populations of Damask Rose from Iran. J Agr Sci Tech. 2019;21(2):423-37.

5. Dagli R, Avcu M, Metin M, Kiymaz S, Ciftci H. The effects of aromatherapy using rose oil (Rosa damascena Mill.) on preoperative anxiety: A prospective randomized clinical trial. Eur J Integr Med. 2019; 26: 37-42. https://doi.org/10.1016/j.eujim.2019.01.006

6. Heydari $N$, Abootalebi $M$, Jamalimoghadam $N$, Kasraeian $M$, Emamghoreishi $M$, Akbarzaded $M$. Evaluation of aromatherapy with essential oils of Rosa damascena for the management of premenstrual syndrome. Int J Gynaecol Obstet. 2018;142(2):156-61. https://doi.org/10.1002/ijgo.12534

7. Niazi M, Hashempur MH, Taghizadeh M, Heydari M, Shariat A. Efficacy of topical rose (Rosa damascena Mill.) oil for migraine headache: A randomized doubleblinded placebo-controlled cross-over trial. Complement Ther Med. 2017;34:35-41. https://doi.org/10.1016/j.ctim.2017.07.009

8. Hamdamian S, Nazarpour S, Simbar M, Hajian S, Mojab F, Talebi A. Effects of aromatherapy with Rosa damascena on nulliparous women's pain and anxiety of labor during first stage of labor. J Integr Med. 2018;16(2):120-5. https://doi.org/10.1016/j.joim.2018.02.005

9. Fatemi F, Golbodagh A, Hojihosseini R, et al. Antiinflammatory effects of deuterium-depleted water plus Rosa damascena Mill. essential oil via cyclooxygenase-2 pathway in rats. Turk J Pharm Sci. 2020;17(1):99-107. https://doi.org/10.4274/tjps.galenos.2018.24381

10. Yi F, Sun J, Bao X, Ma B, Sun M. Influence of molecular distillation on antioxidant and antimicrobial activities of rose essential oils. LWT. 2019;102:310-6. https://doi.org/10.1016/j.Iwt.2018.12.051

11. Mohebitabar S, Shirazi M, Bioos S, Rahimi R, Malekshahi F, Nejatbakhsh F. Therapeutic efficacy of rose oil: A comprehensive review of clinical evidence. Avicenna J Phytomed. 2017;7(3):206-13.

12. Mahabob N, Mohan J. Preparation of mouthwash and gel from Rosa damascena Mill and evaluating its effectiveness-An in vivo analysis. J Pharm Bioall Sci. 2019;11(Suppl 2):S198-202.

https://doi.org/10.4103/JPBS.JPBS_294_18
13. Szabó MA, Varga GZ, Hohmann J, et al. Inhibition of quorum-sensing signals by essential oils. Phytother Res. 2010;24(5):782-6. https://doi.org/10.1002/ptr.3010

14. Eris R, Ulusoy S. Rose, clove, chamomile essential oils and pine turpentine inhibit quorum sensing in Chromobacterium violaceum and Pseudomonas aeruginosa. J Essent Oil Bearing Plants. 2013;16:12635. https://doi.org/10.1080/0972060X.2013.794026

15. Zhang J, Rui X, Wang L, Guan Y, Sun X, Dong M. Polyphenolic extract from Rosa rugosa tea inhibits bacterial quorum sensing and biofilm formation. Food Control. 2014;42:125-31. https://doi.org/10.1016/j.foodcont.2014.02.001

16. Bali EB, Türkmen KE, Erdönmez D, Sağlam N. Comparative study of inhibitory potential of dietary phytochemicals against quorum sensing activity of and biofilm formation by Chromobacterium violaceum 12472, and swimming and swarming behaviour of Pseudomonas aeruginosa PAO1. Food Technol Biotechnol. 2019;57(2):212-21. https://doi.org/10.17113/ftb.57.02.19.5823

17. Çepni E, Gürel F. Bitkilerden elde edilen anti quorum sensing bileşikleri ve yeni ilaç geliştirmedeki potansiyelleri. Turk Mikrobiyol Cemiy Derg. 2011;41(4):131-8. https://doi.org/10.5222/TMCD.2011.131

18. Yeniçeri M. Bakterilerde quorum sensing ve antimikrobiyal dirence olan etkisi. Cumhuriyet Üniv. Sağ. Bil. Enst. Derg. 2018;(3)1:41-5.

19. Bosgelmez-Tinaz G. Disruption of bacterial cell-to-cell communication (Quorum sensing): A promising novel way to combat bacteria-mediated diseases. MUSBED. 2013;3(3):159-63. https://doi.org/10.5455/musbed.20130910085643

20. Zgoda JR, Porter JR. A convenient microdilution method for screening natural products against bacteria and fungi. Pharm Biol. 2001;39(3):221-5. https://doi.org/10.1076/phbi.39.3.221.5934

21. McClean KH, Winson MK, Fish L, et al. Quorum sensing and Chromobacterium violaceum: exploitation of violacein production and inhibition for the detection of $\mathrm{N}$-acylhomoserine lactones. Microbiology (Reading). 1997;143(Pt 12):3703-11. https://doi.org/10.1099/00221287-143-12-3703

22. Morohoshi T, Kato M, Fukamachi K, Kato N, Ikeda T. $\mathrm{N}$-Acylhomoserine lactone regulates violacein production in Chromobacterium violaceum type strain ATCC 12472. FEMS Microbiol Lett. 2008;279(1):12430. https://doi.org/10.1111/j.1574-6968.2007.01016.x 23. Blosser RS, Gray KM. Extraction of violacein from 
Chromobacterium violaceum provides a new quantitative bioassay for $\mathrm{N}$-acyl homoserine lactone autoinducers. J Microbiol Methods. 2000;40(1):47-55. https://doi.org/10.1016/s0167-7012(99)00136-0

24. Packiavathy IASV, Agilandeswari P, Musthafa KS, Pandian SK, Ravi AV. Antibiofilm and quorum sensing inhibitory potential of Cuminum cyminum and its secondary metabolite methyl eugenol against Gram negative bacterial pathogens. Food Res Int. 2012;45(1):85-92.

https://doi.org/10.1016/j.foodres.2011.10.022

25. O'Toole GA, Kolter R. Initiation of biofilm formation in Pseudomonas fluorescens WCS365 proceeds via multiple, convergent signalling pathways: A genetic analysis. Mol Microbiol. 1998;28(3):449-61. https://doi.org/10.1046/j.1365-2958.1998.00797.x

26. Tofighi Z, Molazem M, Doostdar B, et al. Antimicrobial activities of three medicinal plants and investigation of flavonoids of Tripleurospermum disciforme. Iran J Pharm Res. 2015;14(1):225-31.

27. Shohayeb M, Abdel-Hameed ESS, Bazaid SA, Maghrabi
I. Antibacterial and antifungal activity of Rosa damascena MILL. essential oil, different extracts of rose petals. Glob J Pharm. 2014;8(1):1-7. https://doi.org/10.5829/idosi.gjp.2014.8.1.81275

28. Mahboubi M. Rosa damascena as holy ancient herb with novel applications. J Tradit Complement Med. 2015;6(1):10-6. https://doi.org/10.1016/j.jtcme.2015.09.005

29. Ulusoy S, Boşgelmez-Tinaz G, Seçilmiş-Canbay $H$. Tocopherol, carotene, phenolic contents and antibacterial properties of rose essential oil, hydrosol and absolute. Curr Microbiol. 2009;59(5):554-8. https://doi.org/10.1007/s00284-009-9475-y

30. Baydar H, Göktürk Baydar N. Yağ gülü (Rosa damascena Mill.)'nde distilasyon ürünlerinin uçucu yağ ve fenolik madde içerikleri ile antiradikal ve antioksidan aktiviteleri. Tar Bil Der. 2017;23:1-9.

31. Yi F, Sun J, Bao X, Ma B, Sun M. Influence of molecular distillation on antioxidant and antimicrobial activities of rose essential oils LWT. 2019;102:310-31. 